\title{
De las normas como compromisos prácticos y de la locura como incumplimiento de tales compromisos
}

\author{
Miguel Ángel Quintana PaZ \\ Universidad Pontificia de Salamanca
}

RESUMEN. Desde un punto de vista postmetafísico y a partir de los argumentos que nos proporciona (fundamentalmente) un autor como Ludwig Wittgenstein, trataremos de defender la tesis de que las normas en general cobran su carácter normativo de la responsabilidad que se atribuye a cada agente cuando, al actuar en sociedad, se liga a los compromisos que sostienen la posibilidad de que esa acción sea común. Esos compromisos, ya que (en la postmetafísica) no pueden responder ante una instancia ajena a los agentes sociales (metafísica), habrán de tener el cariz práctico (ético-político) de todo lo que atañe en exclusiva a los afanes de los humanos entre sí. Una regla no nos pide que respondamos de su cumplimiento o no, pero nosotros sí que podemos pedirnos cuentas unos a otros de ese cumplimiento o vulneración a partir de la responsabilidad compartida en la vida social en que pululan tales reglas; de hecho, a aquellos que las incumplen gravemente, siempre podemos apartarlos definitivamente de nuestra vida en sociedad adjudicándoles «maldad» 0 «locura» persistente. Al caer así en la cuenta de que las reglas tienen sólo este género de responsabilidad mutua, una nueva regla se nos puede hacer plausible junto a las demás: la de tolerar la posibilidad de otros compromisos con diferentes reglas en otros contextos que hayan generado otras responsabilidades diferentes a las nuestras.
AbSTRACT. From a post-metaphysical point of view, and making use of arguments provided mainly by Ludwig Wittgenstein, I will try to endorse the following thesis in this paper: that norms in general receive their normative character only from the responsibility that is attributed to each agent when they act in a social context. This context is full, thus, of normative commitments as its sine qua non. Since (in post-metaphysics) these commitments cannot co-respond to any other (metaphysical) instance apart from the social agents, we have here a kind of commitments very near to what traditionally has been conceived as an ethical-political notion of responsibility. A rule does not request us to fulfil it, but we humans do request others to do so; if a rule has not been obeyed, we ask for accounts of its unfulfillment, or apply different kinds of measures against the violator. In fact, if someone fails to fulfil an important rule, it is even possible to separate them from our life in society, pronouncing them to be absolutely «evil» or persistently «mad». When we realize in such a way that the power of rules dwells only on this sort of mutual responsibility, a new rule (a rule of tolerance) can become reasonable for us: the rule of tolerating the possibility of other commitments with different rules in alien contexts that have generated other responsibilities different from ours. 
Palabras clave: Wittgenstein, responsabilidad, compromisos, reglas, locura, postmetafísica, tolerancia.

Pongámonos en la condición (en nuestra condición) de que se nos hayan llegado a hacer poco atractivas las autoridades metafísicas (todas las autoridades metafísicas: Dios, la Realidad, el Deber, la Naturaleza, la Comunidad...); es decir, situémonos en la condición de aquel al que se le han derretido entre las manos (acaso asoladas bajo el calor de argumentos como los wittgensteinianos) aquellas instancias que tradicionalmente garantizaban con su autoridad inquebrantable el fundamento último de nuestras normas, nuestras razones, nuestras acciones. Pongámonos, pues, en condiciones de arrostrar el reto de la postmetafísica: ¿cómo podemos seguir sosteniendo que ciertos argumentos son mejores que otros, ciertas afirmaciones más correctas que otras, y ciertos actos más apreciables que otros, una vez que no se puede ya reclamar para ciertos argumentos, afirmaciones o actos el privilegio de haber respondido mejor a lo que los fundamentos metafísicos querían de ellos? Reformulemos de nuevo la pregunta: si se acepta el dictum nietzscheano de que «no hay hechos, sino sólo interpretaciones» 1 como fiel diagnóstico de nuestra condición postmetafísica (pues el hecho es siempre la autoridad fundamental, situada más allá de todos nosotros, en suma, metafísica; mientras que la interpretación es siempre un dispositivo bien nuestro, humano bien humano, hecho para lidiar tras los fundamentos con nuestras tenues vidas), si se aceptase tal sentencia, decíamos, ¿cómo es sabemos distinguir luego entre interpretaciones mejores y peores; ${ }^{2}$ entre lo que es verdadero y lo falso, lo correcto y lo incorrecto, lo bueno y lo malo? ¿Y
Key words: Wittgenstein, Responsibility, Commitments, Rules, Madness, Postmetaphysics, Tolerance.

cómo se forman tales interpretaciones, los útiles esos con que nos manejamos en nuestras sociedades?

Parece ineludible, en efecto, reconocer que habrá de existir cierta fuerza que impulse las interpretaciones que «fluyen» en «la vida y el pensamiento» (Z: 173) $)^{3}$ de los humanos; una fuerza que explique por qué nos insertamos unos y otros en continuas prácticas de convicción recíproca; por qué estamos dispuestos a aferrarnos más enfáticamente a ciertos puntos nodales de nuestro trasfondo de interpretaciones; por qué previamente hemos hecho de estos puntos verdaderos «fósiles» (ÜG: 657) o «rocas» (ÜG: 99) en medio del tráfago de la historia; y por qué mientras, en cambio, no nos importa en demasía el abandono de aspectos más «móviles», como la arena llevada por el río (ÜG: 99) de nuestras interpretaciones.

Desde un punto de vista fundamentalista, la fuerza que nos llevaba a actuar normativamente, a tratar de convencer y de ser convencidos si lo creíamos oportuno, era siempre la responsabilidad (la «obligación de responder», según el último diccionario de la RAE) ${ }^{4}$ hacia el fundamento. No podíamos seguir haciendo cualquier cosa una vez que una norma se nos había impuesto por parte de la Realidad, la Humanidad, la estructura de nuestro Pensamiento, la Divinidad, «el desconocido libre»5, o cualquier otra instancia metafísica: ya que habíamos de responder ante esa instancia que nos la imponía, éramos responsables ante ella y ante su autoridad (la cual, eventualmente, podría castigarnos de diversos modos si no respondíamos a sus requerimientos normativos: si no respondo ante la estructura de lo real al edificar 
un puente, éste se puede caer; si no respondo ante las leyes del pensamiento o de la moralidad, estoy automáticamente excluido del ámbito racional; si no respondo a los mandamientos del ente divino, éste me puede enviar diez plagas; etcétera). Parejo género de responsabilidad hacia el fundamento podía revestirse de muchas formas y colores: tanto cabía pensar en una responsabilidad hacia un fundamento externo de todas nuestras interpretaciones, una «responsabilidad frente a la realidad» que se daría «si preguntásemos: «¿y bien, respecto a qué es todo esto responsable?»» (LFM: 240); como se podría, igualmente, pensar en la responsabilidad de unas interpretaciones que han de resultar coherentes «respecto a otras» (LFM: 240) ${ }^{6}$.

Ahora bien, el impulso para el acatamiento de normas desde un punto de vista postmetafísico no puede seguir tomando ese género de responsabilidad como su fuente de energía: la postmetafísica no nos permite ya mantener la fe en esos fundamentos normativos ante los cuales responder. ¿Significa eso que actuamos «irresponsablemente» (Z: 283) al aplicar nuestras reglas -y que por lo tanto «todo valga», y no haya reglas en realidad? ¿Nos precipitamos así irremediablemente, al haber denostado las instancias metafísicas, en ese género de arbitrariedad cínica que muchos confunden con lo postmoderno? Evidentemente, no: debe seguir habiendo una responsabilidad correlativa al hecho de interpretar normas, algo hacia lo cual tenemos que corresponder (co-responder) cuando actuamos normativamente, pero lo es de un tipo absolutamente distinto. Una realidad [ante la cual corresponder, responsablemente] es que si [verbigracia] yo he decidido para mí llamar a algo «verde rojizo», el resto de la gente no sabría a qué atenerse (LFM: 244).
Nuestra responsabilidad ve desplazarse entonces su objetivo: ya no tratamos de dar respuesta (o corresponder) a un fundamento que nos interpela, sino que simplemente van a ser el resto de los agentes los que nos pidan cuentas, los que nos interpelen por la responsabilidad de nuestras acciones -como la «policía» (LSD: 20-5-36) del lenguaje público común-; y, por ello, si empleo conceptos o normas privados como un insólito «verde rojizo» $-\mathrm{u}$ otras expresiones que ni se usan ni se entienden, como «luz blancuzca» (BF: II, 14) o un «blanco transparente claro» (BF: II, 2)- el resto de agentes no sabrán a qué atenerse con lo que hago, y no les habré co-respondido en las prácticas comunes. La correspondencia y adecuación metafísica ante el fundamento se transmuta en un corresponder postmetafísico ante los demás: desde la correspondencia hacia lo superior nos mudamos a la corresponsabilidad mutua entre todos los embarcados en las prácticas humanas. Y es que la responsabilidad queda como un asunto que no puede sino ser negocio meramente humano, algo que ya nos apuntaba el sentido coloquial de esta palabra (que no en vano se usa preferentemente en la praxis ética y política, cuando nos referimos a la responsabilidad frente a entidades personales, que no inertes: la Verantwortung es casi siempre además Mitverantwortung). La fuerza que mueve el motor de nuestras interpretaciones no reside ya en una obligación de «co-responderse» con fundamentos, sino sólo en el impulso de poder responder ante los demás7: aunque ya sabemos que esto no significa que tengamos que corresponder, «asimilarnos», a lo que todos o la mayoría piensa ahora-como diría Peirce ${ }^{8}$, «el hombre es esencialmente un animal social; pero ser social es una cosa, y ser gregario otra»-. Sólo significa que es ante los demás agentes ante los que he de intentar 
mostrar la legitimidad normativa de mi acción (con la esperanza de lograr la mayor aquiescencia posible -pero no necesariamente aquí o ahora); y que es a mí a quien «incumbe la responsabilidad» ante ellos de esa acción, de sus éxitos y de sus fracasos.

El pensamiento que no se concibe ya como el reconocimiento y aceptación de un fundamento objetivo perentorio desarrollará un nuevo sentido de responsabilidad, tomada, literalmente, como disponibilidad y capacidad de responder a los otros. $^{9}$

La responsabilidad normativa, al convertirse así en una responsabilidad hacia los otros, presupone entonces la existencia de un «compromiso» entre los hablantes al embarcarse en prácticas y usos comunes (no hay responsabilidad sin compromiso), y Wittgenstein no pasa por alto tal cosa: «He de «comprometerme» con su uso [...] «El que uno se comprometa tiene consecuencias»» (M1: 7). Con sólo ponerme a actuar en prácticas sociales que no me pertenecen en exclusiva, que también incumben a otros - son «propiedad pública» (CE: A, 429)-, incurro en compromisos con ellos (la mayor parte de las veces implícitos, pero a veces explicitados mediante contratos, promesas, leyes, reglas de un juego,...); $\mathrm{y}$, por ello, debo responder de tales compromisos ante los demás: si, por ejemplo, «uso «verde» en este caso, tengo que usarlo en otros» (M1: 7), o si juego al fútbol no deberé coger el balón con las manos (aunque ya sabemos que los compromisos podrían algún día cambiar, sin que nada regule «desde arriba» el foro social que cambiaría tanto ese compromiso sobre la regla del fútbol ${ }^{10}$, como el que sustenta lo apropiado de cada término de color). Es decir, los demás me exigirán que actúe de acuerdo con las normas que hemos implantado entre todos en el foro público, y con las cuales enten- demos que uno se compromete al participar en las acciones que ellas regulan: por ejemplo, hemos instaurado la norma práctica de llamar «verde» a ciertas cosas, y entendemos que quien participa en tal práctica se compromete con los demás, verbigracia, no sólo a decir que la bandera libia es de ese color, sino también a no afirmar que la bandera de las Naciones Unidas lo contenga; y de igual forma se compromete, por ejemplo, a no poder decir de una misma superficie que es al mismo tiempo verde y roja ${ }^{11}$. Entrar a participar en prácticas comunes con otros agentes es entrar en una red de numerosos compromisos. Compromisos que, en efecto, no tienen un respaldo metafísico, una especie de fundamentación que explique por qué debo cumplirlos: simplemente, debo hacerlo porque los demás previsiblemente me exigirán responsabilidades si no lo hago, «y eso es todo cuanto hay en ello» (LFM: 271). Naturalmente, los compromisos van modificándose a medida que se mudan históricamente las interpretaciones sociales: pero ello no significa que me pueda escabullir de ellos aquí y ahora apelando escépticamente a otro tiempo o espacio donde no se dan (ÜG: 652); porque la realidad es que aquí y ahora, en la práctica en que me he involucrado, sí que están vigentes, y eso es todo lo que necesitan para ser efectivos (ÜG: 56) -hasta el punto de que si me quiero zafar de alguno de ellos, sólo podré hacerlo razonablemente en sociedad si convenzo a los demás de que lo hago (como Antígona) porque obedezco a otro de los compromisos mutuos, que veo como incompatible con aquel que desprecio (ÜG: 519): es decir, sólo puedo apoyarme en un compromiso para rechazar normativamente otro compromiso de modo razonable (SDE: 22-23); lo cual significa lo mismo que reiterar, ahora más gadamerianamente ${ }^{12}$, que sólo puedo apoyarme en una tradición o uso 
público (crítico) para superar en manera razonable otra tradición o uso.

Uno vendrá a hacerse acreedor, por lo tanto, de algún u otro reclamo de responsabilidad por parte de los demás agentes cada vez que incumpla los compromisos de nuestra red de «vida y pensamiento», en la cual ««tener que» anuncia la actitud que estamos dispuestos a adoptar ante alguien que deje de adoptarlos» ${ }^{13}$. Al proponer una interpretación nos adherimos a ésta «como a algo que estamos dispuestos a defender y de lo cual aceptamos las responsabilidades que se ahí se desprendan»14: con lo que proponer interpretaciones de cualquier tipo (matemático, científico, religioso, estético, político,...) implica ya, a su vez, el estar sumergidos en una práctica de responsabilidades (éticas, políticas, públicas) con respecto a los demás gracias a los compromisos contraídos con ellos: no es difícil colegir entonces que existe, pues, lo que Bambrough ${ }^{15}$ ha llamado una «ética de la creencia» en cualquier tipo de asertos (tanto los éticos como los no estrictamente éticos). Algunos ejemplos de los compromisos implicados en esta ética de haber manifestado que creemos algo (que lo interpretamos de tal y tal modo) son, verbigracia, que anunciamos la actitud que estamos dispuestos a adoptar hacia lo que se muestra en desacuerdo con nosotros, anunciamos la clase de apoyo que somos capaces de obtener para nuestra afirmación en el caso de que sea desafiada [...]. Y somos responsables de lo que asumimos de esta forma: si no podemos sustentar nuestra posición de forma apropiada, pagamos un precio ${ }^{16}$.

No es irrelevante que aparezca aquí ante nosotros una metáfora económica que alude a precios, dinero y pagos. Quizá no podía ser de otro modo, habida cuenta de que uno de los sinónimos de «compromiso» es el de «deuda contraída», y las deudas son ya casi siempre económicas. Y acaso resulte iluminador, en efecto, preconizar con Wittgenstein, en este preciso sentido, que el lenguaje público «es como el dinero» (WC: 33 ): si alguien no cumple «de forma apropiada» los compromisos que contrae, como quien no devuelve un préstamo, puede que vea más adelante cómo se le exige «pagar un precio» para que se responsabilice de ese compromiso incumplido, de ese alejamiento con respecto al nosotros (BGM: I, 61). Ese precio puede estar expresado en toda suerte de unidades monetarias ${ }^{17}$ : acaso, si llamo «verde rojizo» a lo que nadie llamaría así, entonces fracase una práctica común en que yo había pedido a otro agente que me trajese algo de color «verde rojizo»; quizá se me confine a una esfera diferente de la red de normas por hablar de ese «verde rojizo» (se pensará que sólo puedo estar haciendo poesía cuando hablo de esa peregrina manera, y se actuará conmigo como con alguien que está poetizando, no alguien que esté dando órdenes o «hablando objetivamente»; lo cual, a su vez, puede acarrearme ventajas o inconvenientes dependiendo de los agentes con que esté interactuando y su grado de complacencia para con los poetas); tal vez, si insisto en usar palabras que nadie entiende, se me etiquete como a un individuo en extremo extravagante de por sí (tal y como le ocurre al personaje de Belarmino en la novela Belarmino y Apolonio de Pérez de Ayala); posiblemente esa insistencia me lleve a modificar los usos lingüísticos y normativos de la sociedad que me rodea, que acabará considerando deseable adoptar mi costumbre de hablar del color de algunas cosas como «verde rojizo» (y luego me honrará como el precursor profético de esta nueva norma); puede darse también, eventualmente, que se me acabe relegando como a un loco (al menos, un loco con respecto a los colores, ad cetera 
sobrius); y existe, no en menor medida, la probabilidad de que caiga sobre mí el oprobio (ÜG: 367) por mi error al no saber aún hablar de colores (ni saber que en castellano no existe un «verde rojizo», porque son colores no inmediatos en los espectros de gamas de color), lo cual se acompañará previsiblemente de una reprensión (ÜG: 495) que se reputará que merezco por ello. La decisión entre estos y otros $\operatorname{precios}^{18}$ a pagar, así como la misma decisión de si tengo que pagar un precio, es potestad exclusiva del juicio de los agentes, única instancia competente para dirimir aquí con autoridad: es imposible predeterminar en un estudio teórico como el que aquí estamos esbozando, pues, qué precios se pagarán por qué cosas, y cuándo se procederá a solicitar estos adeudos o se pasarán indiferentemente por alto porque los demás deciden mostrar hacia mí cierta indulgencia (BGM: I, 118).

En ocasiones, empero, lo cierto es que si la sociedad interpreta (postmetafísicamente, sin guías más allá de sus interacciones) que alguien ha violado sus compromisos regulativos de un modo que ella pondera como especialmente radical, entonces se ponga en marcha cierta operación también radical sobre ese agente vulnerador de sus responsabilidades. Orwell ${ }^{19}$ ya estudió detenidamente este tipo de comportamiento humano: al encontrarnos con personas con las que diferimos en cuestiones de principio -lo que hemos llamado nodos especialmente «fosilizados» (ÜG: 657) de nuestra red de creencias-, siempre podemos amarrarnos al recurso sencillo de decretar que, si ellos osan diferenciarse tanto de nosotros en asuntos normativos, sólo puede ser porque nos encontramos ante «locos o herejes» ${ }^{20}$. Es decir, la sociedad interpreta en ese caso que aquél que incumple gravemente sus compromisos para con ella es un agente que debe de poseer al menos una de estas dos lacras (y habrá de pagar el precio correspondiente por ello): O bien (y ésta es la primera lacra) se trata de un individuo que carece de la capacidad intelectiva suficiente como para participar de nuestras prácticas normativas más esenciales -ya porque sea un $\operatorname{loco}^{21}$ o un tonto (BGM: VI, 35) permanente, ya porque se vea momentáneamente perturbado (ÜG: 71)-, y por lo tanto, a pesar de su voluntad de compartir ciertas acciones «cuerdas» o «inteligentes» con nosotros, no podemos dejar que haga tal cosa pues las entorpecerá; o bien (y esta es la segunda lacra que le podemos atribuir) se trata de un agente que sí atesora la capacidad mental que le permitiría hacer tal cosa, pero que decide de propósito no hacerlo, y ello es así por su voluntad decidida de resultar divergente respecto a la sociedad: su voluntad de ser un herético, un disidente, un cismático, un personaje conflictivo, un ser malvado. «Loco»y «hereje», pues, no son sino los nombres que se dan a los infractores más rotundos de los compromisos que acomunan a los agentes sociales en una red de responsabilidades respecto a sus acciones hermenéuticas. Ambos responden a la necesidad que tiene la sociedad de hacer lo que Barbara Herrnstein Smith ${ }^{22}$ ha llamado «privilegiar lo propio mediante el expediente de «convertir en patológico» [pathologizing] al Otro», lo cual «sigue siendo el movimiento clave y el objetivo definidor de toda axiología» o racimo de normatividad.

El segundo caso reseñado, el del «hereje» 23 , es especialmente representativo para entender el juego de responsabilidades y compromisos mutuos en el trasfondo social de interpretaciones. Al hereje se le puede combatir mediante numerosas 24 estrategias, pero quizás lo interesante es que todas ellas implican seguramente un grado elevado de esto 
mismo: de combate, de lucha-«bekämpfen» (ÜG: 609-612)-, mientras que hacia el loco o el necio suele cundir más frecuentemente el simple desprecio o la conmiseración. Algunas discrepancias heréticas veniales con respecto a los compromisos contraídos pueden seguramente resolverse mediante una negociación entre los implicados 25 ; pero el incumplimiento grave de compromisos desencadena medidas crecientemente contundentes respecto al infractor, que pueden llegar hasta la violencia ${ }^{26}$. Pues todo lo que tiene ese compromiso para sostenerse, ausente un correlato metafísico que lo alimente, es esa capacidad de ejecutarlo en sociedad: y quien se niega a colaborar en tal ejecución se hace reo del más grave atentado contra tal instancia normativa, el de atacar su sostenibilidad intersubjetiva -su única sostenibilidad.

En estas circunstancias, quizá estemos en disposición de colegir alguna consecuencia específicamente ética a partir de estas consideraciones epistemológicas: desde el presente análisis postmetafísico de la normas que, de la mano de reflexiones wittgensteinianas, venimos aquí bosquejando, ¿cabe emitir alguna clase de recomendación moral hacia los agentes implicados en alguna práctica de conflicto semejante? Creo que la respuesta a esta pregunta (a diferencia, verbigracia, de lo que piensa Lovibond ${ }^{27}$ ), es positiva: sí que cabe hacer algún tipo de exhortación (por pequeña que ésta sea) en tales circunstancias; ya que, si a los principios que causan el enfrentamiento radical se les ha sustraído la perentoriedad irrefutable de los fundamentos metafísicos, entonces quizá pueda amortiguarse un tanto la violencia -argumentativa y externa a la argumentación ${ }^{28}$ - que, a partir de estos, existe la tentación de ejercer contra el disidente. Cuando se repara en que el «hereje» no está atentando contra los principios inmaculados radicados en un empíreo más o menos sagrado e inmutable (sino que, simplemente, está aludiendo a compromisos que tal vez sean efectivos en otras prácticas y contextos), entonces puede que se modere la sacra ira que amenazaba tonante con descargarse sobre su testa, y ello gracias a nuestra capacidad de imaginar $^{29}$ esos otros contextos (en los cuales no resultaría tan flagrantemente inadaptado a las circunstancias).

\section{Podríais decir:}

«para ser un error, esto es demasiado grande». Si de repente escribieras números en la pizarra y dijeras: «Ahora voy a sumar», y después dijeras «2 y 21 son 13», etcétera, yo diría: «Esto no es un error» (LC: IV, II).

En efecto, cuando lo que el otro dice suena «demasiado absurdo» (ibíd.), quizá no es que esté incumpliendo flagrantemente los compromisos de nuestra red de responsabilidades (ni aún menos, la «responsabilidad ante los fundamentos necesarios»): sino que, simplemente, acaso esté aludiendo a otra red de compromisos diferentes, con lo que, puesto que no ha suscrito los compromisos de nuestra red, tampoco luego los ha incumplido. Como nuestra red no tiene una primacía metafísica sobre esos otros compromisos, entonces la tolerancia se vuelve una opción más atractiva (normativamente) que si ya contásemos con la única verdadera red de interpretaciones y normas que se corresponde a lo único a lo que hay que corresponderse. Naturalmente, esa tolerancia tiene a su vez los límites y circunstancias de aplicación que los agentes normativos vayan estipulando, según su interpretación de tal norma de la tolerancia: «Tendría que ver la suma, ver de qué modo se hace, lo que él deduce de ella, bajo qué circunstancias la hace, etcétera» (ibíd.). Y es que tampoco 
la virtud (dianoética y ética) de la tolerancia se erige (ni se puede erigir) como fundamento absoluto. Pero es una virtud que se ve extraordinariamente favorecida tras que se nos haya eximido de compromisos con respecto a principios normativos metafísicos e inexorables «que no perdonan nunca» (BGM: I, 118). Cuando el perdón sólo depende de nosotros, es más sencillo perdonar ${ }^{30}$.

Hay otra reflexión que también coadyuva a favorecer la implantación de una norma que ordene la tolerancia, aparte de lo que ya la fomenta esta debilitación de los fundamentos propios. Y tal reflexión concierne no sólo al hereje, sino asimismo a los casos en que nos hallamos ante el otro género de desavenido radical, el de quien está aquejado de locura o enajenación. Pues la diferencia entre quien no cumple sus compromisos respecto a otros agentes y quien sí lo hace se desdibuja un tanto una vez se haya aceptado que se deba imprimir un giro postmetafísico a nuestras ideas sobre la normatividad: y esto es así porque, ausentes los fundamentos de tales compromisos, lo único que nos queda es el número finito de casos de realización de estos, sin que nada les subyaga como para garantizar su perennidad histórica o su aplicación unívoca en el presente. Y, por ello, no se puede sino consentir historicistamente con la especie de que posiblemente algún día el loco y el hereje dejen de ser contemplados como tales, o avenirse incluso con la idea de que tal vez hoy ya esté modificándose, con los usos precisamente de ese loco y ese hereje, el significado (compuesto sólo por esos y otros usos finitos) de lo que ha de valer como «loco»o «hereje». Al igual que nunca está predefinido a priori, metafísicamente, el modo en que el agente ha de interpretar una norma (y por ello hace falta un compromiso entre los agentes implicados), tampoco está predefinido el modo en que se debe aplicar la distinción entre el loco o el hereje y los demás; y tal distinción se definirá, pues, en función del compromiso práctico de los agentes implicados: por consiguiente, la susodicha distinción no será más inexorable de cuanto nosotros seamos inexorables (BGM: I, 118), y con ello gana plausibilidad la idea de tolerar un espacio intermedio sin acotación estricta, con una frontera «debilitada»y «vaga» 31 , de lo que sea la herejía o la insensatez. Ya hemos mencionado antes el ejemplo de quien usa contra las interpretaciones de su logos social el concepto normativo de «verde rojizo»: puede que finalmente pase a ser considerado poeta quien previamente sólo era un loco, o que el hereje llegue a fundar una escuela en que hablar de «verde rojizo» sea tan ortodoxo como para un hablante del castellano contemporáneo puede resultar heterodoxo el suponer que existe un color así. Quien habla de «verde rojizo» diverge frente a los usos actuales en que se habla de colores; pero, a la vez, ya al hablar de «verde rojo» está dando la posibilidad de que se vaya implantando en público un nuevo uso en que sí se hable de «verde rojizo»: y nada le impide estar incoando ${ }^{32}$ esa nueva práctica, que sólo depende de usos como ése de agentes como él. Ninguna delimitación apriórica de lo «normal» excluye de modo preciso que cierta cosa que ahora nos parezca «locura» no pueda dejar de serlo, ni asegura tampoco que algo normal nunca pueda llegar a contemplarse como «locura»; y, por ello, quizá los usos actuales que nos parecen extraños ya estén principiando esa modificación de los límites entre «normal» $\mathrm{y}$ «loco»:

Es fácil imaginar y figurarse con todo detalle sucesos que, si llegasen a ocurrir, nos sumirían en la desconfianza respecto a todos nuestros juicios. 
Si alguna vez viera desde mi ventana un entorno totalmente diferente al que se ve desde ella habitualmente, si las cosas, los humanos y los animales se comportasen como nunca se habían comportado, aseveraría algo así como: «Me he vuelto loco»; pero eso sería sólo una expresión de que abandono el intento de ubicarme en el entorno. Y lo mismo podría pasarme en matemáticas. Podría parecerme, por ejemplo, que continuamente me equivoco al calcular, de manera que ninguna solución me pareciese satisfactoria.

Sin embargo, para mí lo importante de ello estriba en el hecho de que no hay una frontera precisa entre un estado semejante y el estado normal (Z: 393; el subrayado es mío; véase también BGM: I, 116).

Nada nos garantiza que algo pertenezca a un estado normal o a un estado perturbado: pues sólo a lo largo de la historia se van redibujando una y otra vez los límites imprecisos entre lo normal y lo trastornado. Por ello es comprensible que Wittgenstein siempre pensase que la diferencia entre cordura e insania representaba más bien una cuestión de (voluble) grado ${ }^{33}$ que de abismos categoriales entre ambas ${ }^{34}$ : «iMira al hombre sano que hay en el lunático! ( $Y$ al loco que hay en ti mismo)» (MS 120: 15-2-38):

Si me volviese loco, lo que más temería sería vuestra actitud de «sentido común». Que os tomaríais como una cuestión de hecho que yo habría de estar sufriendo sin duda alucinaciones ${ }^{35}$.

...Porque esa actitud «de sentido común» es todo cuanto decide, de hecho, que alguien se vea relegado como loco, o como hereje. Y su mutabilidad histórica en cuanto que actitud es lo que recupera como una virtud recomendable, desde una perspectiva postmetafísica, la disponibilidad para abrirse ante trasfondos interpretativos con compromisos diversos al nuestro y que, si no fuésemos conscientes de tal historicidad, tal vez nos apresuraríamos a tachar de «locos»o «heréticos». Nuestras reflexiones wittgensteinianas sobre la normatividad propician que se recupere la virtud, pues, de «seguir abierto a nuevos argumentos. La gente a la que no pudiera enseñarse esto nos parecería deficiente» (VB: 411) ${ }^{36}$. Algo que bien se podría relacionar ${ }^{37}$ con el «prejuicio de

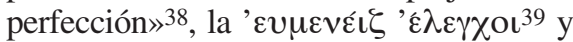
el «principio de caridad» 40 o la actitud de «escucha» 41 de la filosofía más reciente sobre la interpretación ${ }^{42}$. Todos ellos nos enseñan lo que gadamerianamente cabe denominar «el arte de poder no tener razón» ${ }^{43}$. En tal arte y virtud se entrecruzan de nuevo (como acaeció antes, cuando nos referimos a la cuestión general de la responsabilidad) la normatividad en sentido lato y la normatividad concreta que atañe a la filosofía moral: pues es una norma a la vez ética y a la vez dependiente de nuestro análisis general sobre las normas la que nos invita a aproximarnos hacia trasfondos interpretativos bien diferentes del propio con la humil$\operatorname{dad}^{44}$ de no adjudicarles férreamente $\mathrm{ad}$ aeternum el marbete de «locos insensatos» o «pérfidos herejes». En otras palabras, la reflexión metanormativa (sobre las normas) que venimos conduciendo en este trabajo nos empezaría a conducir ya hacia una norma (ético-política) concreta: la de la tolerancia ante otros contextos normativos. Tal tolerancia es una actitud que se deduce de algún modo, como repercusión ineluctable, de las consideraciones postmetafísicas (de cariz wittgensteiniano) que hemos venido haciendo acerca de otros contextos normativos en su relación con el propio; de estas consideraciones metanormativas se extrae, pues, una consecuencia sobre las propias normas (éticas) que procurar añadir al conjunto de normas éticas que ya aceptamos como más plausibles. Si 
analizamos la naturaleza (histórica, contingente) de los compromisos normativos que sostenemos en general con los demás agentes, ello nos conduce a que se nos haga razonable un nuevo compromiso (ético, de tolerancia) acerca de las normas de los demás agentes (y, por ende, de tolerancia ${ }^{45}$ hacia ellos como agentes, en su interacción con nosotros): pues no podemos oponerles a ellos una presunta superioridad metafísica de las interpretaciones normativas propias, que no es tal ${ }^{46}$. Como aseveraría Gadamer:

El alma de mi filosofía hermenéutica es que afirmo que comprender al otro significa, hasta cierto punto, conceder que el otro tiene razón. Y ello transforma nuestro propio ser. Así que, de hecho, creo que, puesto que hemos crecido en esta civilización mundial, debemos por consiguiente aprender a ver la posible verdad en las razones del otro, y a dudar de nuestras propias razones ${ }^{47}$.

Respecto a este nuevo compromiso de apertura hacia los demás, dos son las actitudes (una mejor, otra peor -desde ese mismo punto de vista normativo) que se pueden adoptar. La actitud que la norma recomienda es la del «coraje» del pensamiento (VB: 296) para entrar en prácticas de comprensión de trasfondos diferentes; la actitud que la norma denigra es la que le es opuesta, la cobardía de un pensamiento que se queda anclado en sus interpretaciones como si éstas fuesen definitivas. No es difícil coincidir aquí con Peter Winch y reputar «asombroso e importante que él [Wittgenstein] use un concepto «ético», como coraje» ${ }^{48}$ para referirse a una cuestión que parecería meramente epistémica (esto de abrirse al conocimiento e interacción con el trasfondo de interpretaciones de otros agentes); sin embargo, el mismo Winch pronto constata sin dificultad que es precisamente valentía lo que hace falta para emprender ese tipo de acción tolerante que nos viene ordenada por parte de la norma de tolerancia extraída de un análisis postmetafísico de las normas:

Hace falta coraje para poner en cuestión las formas familiares de pensar, para tomarse en serio la idea de que no estamos constreñidos a pensar del modo acostumbrado, la idea de que hay otras posibilidades. No se trata sólo de que ello sea [...] psicológicamente agotador [sino que] incrementa la posibilidad de que entremos en conflicto con otra gente, de que nos expongamos a la perspectiva de largas y difíciles discusiones, a la ruptura de amistades y de relaciones con colaboradores, o incluso a cosas peores ${ }^{49}$.

Riesgos de todo tipo nos acechan si empezamos a imaginar y a proponer a los demás que las interpretaciones podrían ser diferentes de como tradicionalmente lo han sido, debido a que esta su evolución histórica hasta el presente es mera contingencia; si comenzamos a proponer interpretaciones que no están en concordancia con las que tradicionalmente se venían sosteniendo y previsiblemente se sostendrán: interpretaciones novedosas que podrían acarrearnos a nosotros mismos la sanción de ser evaluados como «locos o herejes». Y, al incrementarse el riesgo, se incrementa consecuentemente el coraje que nos es preciso reunir antes de aceptarlo para emprender ese tipo de acción de comprensión de trasfondos interpretativos ajenos que la postmetafísica nos muestra como deseable, si es que queremos ser consecuentes con la falta de fundamentos metafísicos y eternos que hemos llegado a atisbar en este nuestro propio trasfondo de interpretaciones. La alternativa opuesta a aceptar valientemente tales desafíos es la de intentar disimularse bajo la piel de un «hombre razonable» (ÜG: 219) que nunca tiene ciertas dudas 
(ÜG: 220) especialmente subversivas del flujo general de vida y pensamiento en que mora; es esta la cobardía de quien no sólo intenta siempre obedecer sumisamente las reglas de «decorum cognitivo» ${ }^{50}$ ya dadas en su contexto, sino que tiende a pensar que éste es la encarnación inmanente de un orden metafísico que trasciende sus meras acciones («así son las cosas»); es esta la pusilanimidad de lo que Wittgenstein denominaba, en términos no (sólo) políticos, un «pensador burgués»,

cuyos pensamientos tenían el fin de ordenar las cosas dentro de una comunidad dada. No pensó sobre la esencia del Estado -o no lo hizo con gusto- sino sobre la manera de ordenar racionalmente este Estado. El pensamiento de que este Estado no es el único posible lo intranquilizaba en parte y en parte le aburría. Quería llegar lo más rápidamente posible a reflexionar sobre las bases de este Estado. Ahí estaba su capacidad y su verdadero interés; en tanto que la verdadera reflexión filosófica lo intranquilizaba, hasta que podía dejar a un lado como algo trivial su resultado -cuando obtenía alguno (VB: 89) ${ }^{51}$.

En general, naturalmente, es tan impracticable (e incluso difícilmente deseable) la valentía desbocada -que puede superar los límites de la imprudencia temeraria- como el aburguesamiento apocado sumo -que equivaldría a la carencia de cualquier acción, pues ya hemos visto que hasta en el más simple acatamiento de reglas supone una interpretación de un compromiso común $\mathrm{y}$, por ello, algo de riesgo (el riesgo de que acaso los demás no consideren pertinente nuestra interpretación)-. Lo cierto es que, entre un punto y otro de un continuo, estamos en tensión entre nuestras acciones interpretativas más heroicas y rompedoras (sobre las que pesa la amenaza de la locura y la necedad) y nuestras acciones interpretativas más pacatas, inerciales y vulgares (que se exponen tanto al peligro de la caída en las redes de la metafísica, como a la asechanza de ignorar la plausibilidad de la tolerancia que se deriva del hecho de que tal metafísica ya no sea, tras Wittgenstein, defendible). Oscilamos como intérpretes, como actores del drama social en común, entre uno y otro extremo, sin que haya una receta metafísica que nos pueda revelar en qué punto preciso entre ambos flancos tirantes hemos de ubicarnos. Tal es nuestra condición postmetafísica $^{52}$.
1 F. Nietzsche, «Jenseits von Gut und Böse», en Sämtliche Werke, vol. 5, DTV-W. de Gruyter, Múnich-Berlín-Nueva York, 1988, § 22.

2 Que la noción de interpretación no exime de, sino por el contrario obliga a tratar de, decidir qué interpretaciones son mejores que otras (pues la libertad de la interpretación no equivale a la arbitrariedad, sino que trae consigo los riesgos de toda responsabilidad), nos lo recuerda elegantemente G. Vattimo, Oltre l'interpretazione, Laterza, Roma-Bari, 1994, 4.

3 Para lo que sigue, las obras de Ludwig Wittgenstein (dado el especial respaldo que en este autor encontraremos a nuestras tesis) se citarán en el cuerpo del texto y con las siguientes abreviaturas (se relacionan las obras en versión original pues esta es la edición que manejamos y traduciremos nosotros mismos, excepto cuando la versión española sea nuestra): BF: Bemerkungen über die Farben / Remarks on Colour, Blackwell, Oxford, 1977; BGM: Bemerkungen über die Grundlagen der Mathematik / Remarks on the Fundaments of Mathematics, Blackwell, Oxford, 1978; CE: «Cause and Effect: Intuitive Awareness», en J. C. Klagge y A. Nordmann (eds.), Philosophical Occasions 
1912-1951, Hackett, Indianápolis, 1993, 409-425; LC: Lectures and Conversations on Aesthetics, Psychology and Religious Belief, Blackwell, Oxford, 1966; LFM: Lectures on the Foundations of the Mathematics, Harvester Press, Hassocks, 1976; M1: G. E. Moore, «Wittgenstein's Lectures in 1930-33», Mind, vol. 63 (1954), 1-15; MS: Manuscripts (manuscritos no editados del Nachla $\beta$, citados según la catalogación de G. H. Von Wright [«The Wittgenstein Papers», en Wittgenstein, Blackwell, Oxford, 1982, 35-62] y accesibles en The Wittgenstein Nachlass: The Bergen Electronic Edition (edición facsímil en CD-ROM a cargo de los «Wittgenstein Archives» de la Universidad de Bergen), Oxford U. P., Oxford, 2000; RLF: «Some Remarks on Logical Form», Proceedings of the Aristotelian Society, vol. supl. IX (1929), 162171; SDE: R. Rhees (ed.): «Some Developments in Wittgenstein's View of Ethics», Philosophical Review, 74 (1965), 17-26; TLP: Logische-philosophische Abhandlung / Tractatus logico-philosophicus, Routledge, Oxford, 1922; ÜG: Über Gewi_heit / On Certainty, Blackwell, Oxford, 1979; VB: Vermischte Bemerkungen / Culture and Value, Blackwell, Oxford, 1980; WC: L. Wittgenstein-O. K. Bouwsma, Últimas conversaciones, trad. de M. Á. Quintana Paz, Sígueme, Salamanca, 2004; Z: Zettel, Blackwell, Oxford, 1967.

${ }^{4}$ En inglés se emplean dos términos con este sentido, responsibility y answerability, reservando la filosofía para el primero generalmente la esfera de lo político-moral, mientras que el segundo se presta con más versatilidad a cuestiones de gnoseología y metafísica (la «respuesta» al mundo como correspondencia con él, adaequatio, o cualquier otro género de relación con tal mundo). Sin embargo, el hecho de que en castellano no exista esta distinción responsibility/answerability nos resultará aquí fecundo para el tipo de analogía que intentamos establecer entre ambos tipos de responsabilidad (dicho coloquialmente: haremos de la necesidad virtud, y aludiremos a ambas acepciones con un mismo término, «responsabilidad»). No creemos, pues, que haya que traducir answerability por una opción diferente de la más correcta desde un punto de vista etimológico (y conceptual, según lo recién apuntado), que es «responsabilidad»; y por ello no podemos estar de acuerdo con Joan Vergés (en su traducción de R. Rorty, El pragmatismo: una versión, Ariel, Barcelona, 2000, 270 y passim) cuando traduce tal answerability como «capacidad de dar respuestas» (lo que diferencia a esta traducción de la correcta es lo que diferencia a cualquier «capacidad» de una «obligación»). De hecho, cuando Wittgenstein, por ejemplo, se dirige en inglés a sus alumnos y se refiere a la responsabilidad en general (hacia el mundo, las leyes del pensamiento, etcétera), no procede como haría algún epistemólogo actual (empleando el término general answerability), sino que utiliza vocablos pertenecientes a la familia de responsibility, incluso para áreas tan distantes de la praxis ética y política como la matemática (véase, para comprobar este extremo, especialmente LFM: cap. Xxv). Cuando escribe en alemán, la cuestión es más simple y elige sin ambages los derivados del lexema de Verantwortung, que aúna, como el español «responsabilidad», los dos términos (moral y epistemológico) en uno: véase, verbigracia, Z: 283. Obsérvese asimismo que otro término de rancio abolengo epistemológico como es el de «correspondencia» alude también etimológicamente a esta obligación de «responder» (co-responder) frente a una instancia normativa (véase su uso en LFM: cap. XXv), como complemento pues de la responsabilidad. Rorty (o.c., 267) cree que todo buen postmetafísico debería abogar, contra Brandom y de la mano de Davidson, por abandonar del todo la noción de «responder» (answer), ya sea ante la realidad o ante los demás; y debería asimismo tratar de sustituirla por la idea de que nuestras aserciones no «representan» las cosas ante las cuales responden, sino que simplemente «tratan sobre ellas» (aboutness): y eso es todo cuanto nos hace falta para comprender su intencionalidad. Aquí, no obstante, y de la mano del uso que hace Wittgenstein de la noción de «responsabilidad», vamos a tratar de defender que se puede, pese a todo, mantener un sentido para la idea de «correspondencia» $\mathrm{y}$ «responsabilidad»: la «correspondencia» como «co-responder» (respondernos unos a otros entre los humanos), y la «responsabilidad» como «responsabilidad práxica», «responsabilidad para con las prácticas comunes»; estos sentidos, «debilitados» mediante una Verwindung de su original sentido metafísico, nos permitirán alejarnos por lo tanto de tal metafísica sin haber tenido que renunciar a los términos en cuestión (esto es también lo que pretende hacer, aunque de otro modo, Brandom cuando mantiene términos como «correspondencia», «representación» u «objetividad» en su enfoque -aunque Rorty, al considerar que esas nociones siguen siempre siendo potencialmente desorientadoras y prometafísicas, se levantará contra él precisamente por este su conservar tales términos). Si se desean ampliar las presentes reflexiones sobre responsabilidad, answerability y responsibility, puede consultarse la amplia nota del traductor en J. McDowell, Mente y mundo, trad. de M. Á. Quintana Paz, Sígueme, Salamanca, 2003, 16-17.

${ }^{5}$ K. Rahner, Hörer des Wortes, Herder, Fráncfort del Braunau, 1971.

6 A uno y otro estilo de fundamentalismo recién mentados en el cuerpo del texto es a lo que podríamos denominar respectivamente (con C. 
Pereda, Vértigos argumentales, Anthropos, Barcelona, 1994, 295-301), «fundamentalismo material» $\mathrm{y}$ «fundamentalismo formal»; si bien, por supuesto, existen varias etiquetas alternativas: «externalismo» e «internalismo»; **»fundamentismo» $\mathrm{y}$ «coherentismo»; «realismo» e «idealismo»; etcétera. E incluso existe el ya consueto intento eclecticista de conjugar lo mejor de ambos extremos: el «fundherentismo» de S. Haack, Evidence and Inquiry. Towards Reconstruction in Epistemology, Blackwell, Oxford, 1993. Donald Davidson, al que en un primer momento no le importó presentar su filosofía antirrepresentacionalista como una suerte de coherentismo ( A Coherence Theory of Truth and Knowledge», en Inquiries into Truth and Interpretation, Clarendon, Oxford, 1986, 183-198), pronto abandonó esta idea («The Structure and Content of Truth». Journal of Philosophy, 87, 279 328, esp. 309): pues, en el fondo, también el requisito de la coherencia impone un canon apriórico e independiente de la interpretación (como cualquier otro fundamento «externo») a los elementos a que se aplica -dicho más davidsonianamente: también la coherencia impone un canon general al término «verdadero», que ignora la enseñanza tarskiana de que «verdadero» es una noción que se halla circunscrita a poder ser aplicada a un lenguaje natural $\mathrm{L}$ como «verdadero en $\mathrm{L}$ », sin que quepa una definición posible de ella aparte de la conjunción contable de infinitos verdaderos en ese lenguaje: véase A. Tarski, «The Semantic Conception of Truth and the Foundations of Semantics». Philosophy and Phenomenological Research, 4 (1944), 341-376-. Véase también D. McCloskey (The Rhetoric of Economics, University of Wisconsin Press, Madison, 1985,47$)$ acerca de este mismo rechazo a definir el concepto de «verdad», con el fin de evitar caer en las redes de una metafísica u otra.

7 Han empleado la noción de responsabilidad con fines normativos que vayan más allá de la ética (concretamente, en la epistemología) autores como L. Code («Toward a «Responsibilist» Epistemology», Philosophy and Phenomenological Research, vol. XVL, n. 1 [1984], 29-50; Epistemic Responsibility, U. P. of New England and Brown University Press, Hanover, 1987) y J. Montmarquet («Epistemic Virtue», Mind, 96 [1987], 482 497; Epistemic Virtue and Doxastic Responsibility. Rowman and Littlefield, Lanham, 1993). Ambos parten del trabajo seminal de E. Sosa («The Raft and the Pyramid: Coherence versus Foundations in the Theory of Knowledge», en P. A. French, T. E. Jr. Uehling y H. K. Wettstein [eds.], Studies in Epistemology. Midwest Studies in Philosophy, vol. V, University of Minnesota Press, Miniápolis, 1980, 3-25), donde se intenta situar la normatividad epistemológica no en una propiedad de los asertos epistémicos, sino en una condición correspondiente al agente que los emite. De ese modo, Code reivindica la responsabilidad como una virtud intelectual, al modo aristotélico; pero este aristotelismo la aleja de las consideraciones que hemos hecho aquí sobre la imposibilidad de justificar cualquier normatividad a partir de fundamentos como son las propiedades, las disposiciones, las funciones (esto se ve especialmente claro en A. Plantinga, «Why We Need Proper Function», Nous vol. 27, n. 1 [1993], 66-82) o cualesquier otras capacidades naturales del agente que las emite; todas esas opciones no son sino reformulaciones de una metafísica de la «Naturaleza» que no nos puede parecer ya excesivamente atractiva. En cuanto a Montmarquet, también adolece de cierto cariz aristotélico en su propuesta (si bien, en su caso, no se ubique en virtudes intelectuales, sino de morales, la determinación de cómo se puede producir normatividad correctamente), por lo que puede ser wittgensteinianamente criticable por parejos motivos. C. Pereda, op. cit. ofrece una interesante concepción epistemológica que conjuga elementos de ambas estirpes, la de virtudes intelectuales y morales.

8 C. S. Peirce, Principles of Philosophy. Collected Papers, vol. 1, Harvard U. P., Cambridge, 1931, IX.

${ }^{9}$ G. Vattimo, op. cit., 52.

$10 \mathrm{P}$. Winch, The Idea of a Social Science and Its Relation to Philosophy, Routledge, Londres, 1963, 93.

${ }^{11} \mathrm{El}$ ejemplo hace intencionadamente referencia al tema debatido en RLF; tema que se ubica justamente en el inicio de la evolución que Wittgenstein emprendería desde sus concepciones del TLP hasta aquellas otras que aquí nos están guiando. Sin embargo, en el artículo recién citado se consideraba todavía tal imposibilidad de que una superficie tuviese a la vez dos colores como «en algún sentido» tautológica (RLF: 167), y, por lo tanto, independiente de la acción de los agentes; lo cual no es el caso ya en la perspectiva que aquí estamos discutiendo.

12 Esta tesis la arguye especialmente Gadamer en textos como «Rhetorik, Hermeneutik und Ideologiekritik. Metakritische Erörterungen zu Wahrheit und Methode», en J. Habermas, D. Henrich y J. Taubes (eds.), Hermeneutik und Ideologiekritik. Theorie-Diskusion, Suhrkamp, Fráncfort del Meno, 1971, 57-82; «Replik», ibíd., 283-317.

13 H. F. Pitkin, Wittgenstein: El lenguaje, la política y la justicia, trad. de R. Montoro, Centro de Estudios Constitucionales, Madrid, 1984, 345-346.

14 R. Bambrough, «Fools and Heretics», en A. P. Griffiths (ed.), Wittgenstein Centenary Essays, Cambridge U. P., Cambridge, 1990, 239-250, aquí 244. 
15 Ibíd., 243.

16 H. F. Pitkin, op. cit., 346-347.

17 S. Cavell, Must We Mean What We Say?, Charles Scribner's Sons, Nueva York, 1969, 92.

18 Merece siquiera una apretada nota la propuesta original de R. Brandom (Making it Explicit: Reasoning, Representing, and Discursive Commitment, Harvard U. P., Cambridge, 1994) acerca de otra posible modalidad del precio (o «sanción») a pagar por parte de quien incumple sus compromisos normativos. Así, cabe pensar que uno reciba lo que él llama una «sanción interna» (ibíd., 44) a la propia red de normas: es decir, la sanción no consiste en algo que se haga con el agente (una «sanción externa» como castigarle física o psíquicamente, o excluirle, o no entenderle,...) sino en algo que se hace con el conjunto de normas que es pertinente aplicarle al agente -lo que Brandom llama «cambiar el estatus normativo» (ibíd., 43) de ese agente-. Por ejemplo, la sanción por no cumplir cierta norma A puede ser la de que se le imponga otra norma B, y la recompensa por cumplir la norma $A$ puede ser que se le de permiso para no cumplir B (a quienes no cumplen la norma de mostrar cierta hoja de un árbol al entrar en cierta cabaña de una tribu, se les aplica la norma que prohíbe asistir a un festival semanal; a quienes sí cumplen la norma de enseñar la hoja, se les exonera de la norma que prohíbe ir al festival para permitirles hacerlo). A Brandom le interesan especialmente este género de normas que dependen unas de otras pues ejemplifican, al pensarlas como una gran red enmarañada, lo que ocurre en el discurso entre los agentes: allí uno, a partir de lo que ha dicho, recibe la norma (el «permiso») de que le permite afirmar otras cosas (las cosas que cabe inferir de esa su aseveración), y recibe también ciertas normas que le prohíben decir otras cosas (todo lo que se repute materialmente incompatible con su enunciado); cómo se comporte ese agente con respecto a esas normas le permitirá a su vez hacer nuevas aseveraciones desde lo dicho y le prohibirá hacer otras, y de este modo holista (ibíd., 45) es como se configura en general la red normativa que son los discursos proposicionales (ibíd., 141-198), en que se van «marcando» (scorekeeping) los permisos y las prohibiciones que se le pueden atribuir a un hablante según sus intervenciones asertivas (véase D. Lewis, «Scorekeeping in a Language-Game», en Philosophical Papers, vol. 1. Oxford U. P., Nueva York, 1983, 233-249). De todos modos, el mismo Brandom reconoce (o.c., 672-673, n. 20) que las sanciones internas acaban generalmente entremezclándose con el resto de sanciones externas, de modo que en nuestra exposición no haremos una diferenciación tajante entre ellas: ambas ponen en marcha por igual el motor de nuestra normatividad, que es el objeto que aquí tratamos de describir.
19 G. Orwell, Shooting an Elephant and Other Essays, Martin Secker \& Warburg, Londres, 1950, 177.

20 De la misma opinión es Wittgenstein (ÜG: 611): «Donde verdaderamente chocan entre sí dos principios, que resultan mutuamente irreconciliables, ahí cada cual considerará al otro como un hereje o un loco (Narren)». Véase también ÜG: 155; y asimismo C. Perelman y L. Olbrechts-Tyteca, La nouvelle rhétorique: Traité de l'argumentation, P.U.F., París, 1958, § 7: «Siempre queda la opción de descalificar al recalcitrante considerándolo como estúpido o anormal»; ibíd, § 13: «La oposición a una norma admitida puede llevar a un hombre a prisión o a un manicomio». La vinculación entre los herejes y los locos aparece asimismo en el Faust goethiano, cuando el canciller proclama en la segunda parte (acto 1, 2): „Dem Pöbelsinn verworrner Geister/ Entwickelt sich ein Widerstand:/ Die Ketzer sind's! die Hexenmeister!/ Und sie verderben Stadt und Land./ Die willst du nun mit frechen Scherzen/ In diese hohen Kreise schwärzen;/ Ihr hegt euch an verderbtem Herzen,/ Dem Narren sind sie nah verwandt». L. Manojlovic («Dve Brankove jereticke price», Politika, 13-11-94, 152) también acierta bien a relatarnos el modo en que las sociedades totalitarias tienden a considerar todas sus ideas directrices «tan naturales y lógicas, [que] sólo los tontos o los enemigos tozudos podrían tener alguna duda respecto a ellas». Y en la misma dirección marcha el famoso trilema de C. S. Lewis -según el cual, alguien que hablase de sí como lo hizo Jesús de Nazaret sólo podía o ser un loco, o ser un blasfemo-hereje, o estar en lo cierto (véase en la misma línea, y a propósito de Ernst Bloch, G. Vattimo, «Il pazzo e il profeta», en Le mezze verità, La Stampa, Turín, 1988, 101-105, especialmente 104: «¿Cómo se distingue, en otras palabras, al loco del profeta?»)-. Por último, H. L. A. Hart («Positivism and the Separation of Law and Morals», en Essays in Jurisprudence and Philosophy, Clarendon, Oxford, 1983, 49-87, aquí 63) también juzgó que aquellos que en sus interpretaciones se alejan del núcleo esencial de una ley, no pueden ser vistos como simples intérpretes con enfoques alternativos, sino que se les debe atribuir la rúbrica de la locura. Para lo que sigue, resulta conveniente recordar que tanto el inglés fool como el alemán Narr puede traducirse tanto por «loco» como por «necio»: en ambos casos, empero, se conserva el sentido peyorativo, pues en ambos casos se trata de calificar a quien no puede compartir, por causas ajenas a su voluntad, nuestros más preciados compromisos (si tal imposibilidad se debe a causas no ajenas a su voluntad, entonces entra en la otra categoría alternativa, la de «hereje»). 
21 L. A. Sass (The Paradoxes of Delusion: Wittgenstein, Schreber, and the Schizophrenic Mind, Cornell U. P., Ithaca, 1994) ha realizado un interesante análisis wittgensteiniano de la locura esquizofrénica, del cual se concluye que la mejor manera de definir a la persona mentalmente enajenada no es la de evaluarle como alguien que emprende acciones irracionales (en el sentido de «perjudiciales para sí» o «carentes de ilación lógica»), ni tampoco como alguien que confunda lo verdadero y lo falso (sufra «alucinaciones»). Por el contrario, el mejor modo de definir con una condición necesaria y suficiente al loco es el de juzgarlo como un individuo que se ha alejado del logos intersubjetivo, del trasfondo común de acciones y comunicación, hasta tal punto que es casi imposible colaborar con él en las prácticas más sencillas o importantes. T. R. Sarbin («Schizophrenic Thinking: A Role Theoretical Analysis», Journal of Personality, 37 [1969], 190-206), proporciona otra perspectiva interesante sobre la locura en relación con lo que aquí viene siendo expuesto; perspectiva en cierto modo precursora de la de Sass: para Sarbin, la locura estaría relacionada con la incapacidad de sobrellevar el carácter potencialmente «entimemático» (véase M. Á. Quintana Paz, «Entimemas y la tortuga de Carroll, o el problema de cómo llegar a ser determinados por reglas racionales», en AA.VV.: ¿Qué Cultura?, Ediciones SM, Madrid, 2004, en prensa) de las interpretaciones mediante las acciones en sociedad: el lunático es aquél al que le resulta imposible prescindir de la posibilidad potencialmente infinita de cuestionar en privado una regla o inferencia, ya que no es lo suficientemente competente como para ayudarse (al modo que hacemos los «cuerdos») del ámbito intersubjetivo de acciones con el fin de dar el «salto» por encima de los infinitos cuestionamientos potenciales -en la forma en que los «sanos» sí damos ese salto, reconfortados por la comunidad de acción con nuestros congéneres-. Véase R. M. Hare, «Theology and Falsification: The University Symposium», en A. Flew y A. MacIntyre (eds.): New Essays in Philosophical Theology, SCM Press, Londres, 1955, 99-103, para otra concepción de la locura como disidencia respecto al trasfondo común de interpretaciones.

22 B. Herrnstein Smith, Contigencies of Value: Alternative Perspectives for Critical Theory. Harvard U. P., Cambridge, 1988, 38.

23 Tomamos aquí el epíteto de «hereje», en la línea de las citas de la nota antepenúltima, con aquel sentido de tal vocablo que porta una considerable carga despreciativa. Si en cierta forma de vida acaeciese lo mismo que cuando «hereje» se puso inopinadamente de moda como término de connotaciones elogiosas para cierto decadentismo
(G. K. Chesterton, «Introductory Remarks on the Importance of Orthodoxy» $\mathrm{y}$ «Concluding Remarks on the Importance of Orthodoxy», en Heretics, John Lane Company, Nueva York-Londres, 1914, 11-24 y 285-305), entonces tal vocablo cesaría de servir para este fin que nos ocupa de cómo denigrar a quienes difieren de nosotros radicalmente; se pueden buscar, en ese caso, sustitutos de su antigua función de dicterio en calificativos como «malvado», «enemigo de la Humanidad», «enemigo del pueblo» (ibsenianamente), «perverso», «colaborador con el mal», y demás panoplia de improperios.

${ }^{24}$ Remitimos a M. Douglas («Self-Evidence», en Implicit Meanings. Essays in Anthropology, Routledge, Londres, 1975) para una descripción general, organizada en cuatro modelos de comportamiento, de los modos en que de hecho se lidia con interpretaciones radicalmente diferentes a las del trasfondo compartido de vida y pensamiento.

25 P. Winch, «Persuasion», en P. A. French, T. E. Jr. Uehling y H. K. Wettstein (eds.): The Wittgenstein Legacy: Midwest Studies in Philosophy, vol. XVII, University of Notre Dame Press, Notre Dame, 1992, 123-137, aquí 135.

26 J. O. Wisdom, «Ludwig Wittgenstein, 19341937», Mind, vol. 61, n. 242 (1952), 258-260, aquí 259, proporciona un ejemplo un tanto aséptico de uno de estos cismáticos: el de quien quisiese jugar al ajedrez sin la reina; y reputa que la mayor contribución de Wittgenstein a la filosofía fue la de plantearse por primera vez seriamente esta pregunta, la de si es posible jugar al ajedrez sin la dama.

27 S. Lovibond, «Realism and Imagination in Ethics», en S. G. Clarke y E. Simpson (eds.), Antitheory in Ethics and Moral Conservatism, State University of New York Press, Albany, 1989, 263.

28 G. Vattimo, o.c., 40-41.

29 Para sendos ejercicios epidícticos sobre la imaginación, fácilmente concordes con lo aquí se dirá de tal potencia del alma, véase O. Wilde, $D e$ profundis, Folio Society, Londres, 1991; y, más directamente vinculado con los afanes wittgensteinianos que aquí nos entretienen, B. R. Crack, Wittgenstein, Frazer and Religión, Londres, Macmillan, 1999. No resulta sorprendente, pues, que los reticentes ante la idea de un Wittgenstein «postmetafísico» como el que aquí estamos presentando hagan de la necesidad virtud, y lleguen incluso a refugiarse en la defensa de una hipotética «falta de imaginación, que es algo bueno en este caso, no algo malo»: J. A. Humphrey, Commentary on Passages from «Wittgenstein on Rules and Private Language», pp. 55-77. http://krypton.mankato.msus. edu/ $\sim$ witt/kpassages4.html, 2001. John Humphrey está comentando a S. A. Kripke (Wittgenstein on Rules and Private Language. An Elementary Exposition, 
Oxford, Blackwell, 1982, 58) y sus referencias al noto experimento mental de N. Goodman -Fact, Fiction and Forecast, Cambridge, Harvard U. P., 1955; «The New Riddle of Induction», Journal of Philosophy, 63 (1966), 281-331- con el concepto «grue»-traducible como «verdul», mejor que como «glauco», término en el que incurre M. J. Frápolli, «En defensa de la epistemología filosófica», Teorema, vol. XVI, n. 3 (1997), 103-114, aquí 113-. Y es que tanto Kripke como Goodman (especialmente en la versión que de este último hace $\mathrm{S}$. Shoemaker, «On Projecting the Unprojectible», The Philosophical Review, 84, 1975, 178-219) inciden en este mismo problema de la posibilidad de una pluralidad de interpretaciones que habíamos «olvidado» cuando «se nos ocurrió un caso, y no otros», y ello por una carencia de apertura en la imaginación hacia casos que, conceptualmente, no estaban excluidos - no había un «límite lógico» (Z: 231) que las impidiese-.

$30 \mathrm{Cf}$. con el lema de otro filósofo paradigmáticamente inmanentista como es Baruch Spinoza: «No ridiculizar, no lamentar y no detestar las acciones humanas, sino comprenderlas» (Tractatus politicus, I, § 4: 80).

31 Para la vaguedad de la diferencia entre el «loco» y el «sabio» (aunque restringida a lo que concierne a la competencia profesional en filosofía) coincide con estas aseveraciones W. V. O. Quine, «Has Philosophy Lost Contact with People?», en Theories and Things, Harvard U. P., Cambridge, 1981, 192.

32 Sobre los problemas específicos de esta incoación de una nueva interpretación (lo que él llama «priming») véase D. Bloor, Wittgenstein, Rules and Institutions, Routledge, Londres, 1997, 96101. En realidad, no se puede decir verdaderamente que alguien haya iniciado un nuevo uso o costumbre normativo hasta que ese uso o costumbre no se ha aceptado por otros agentes (pues, si no, simplemente se habrá hecho un uso privado, erróneo o divergente de la norma social): en esto se asemeja la incoación de costumbres a lo que G. Ryle, The Concept of Mind, Hutchinson, Londres, 1949, 149, llamaría las «success words».

33 J. Hayes, «Wittgenstein's Pupil: The Writings of Maurice O'Connor Drury», en M. O'C. Drury, The Danger of Words and Writings on Wittgenstein, Thoemmes Press, Bristol, 1996, IX-XLIV.

34 El tópico de la cercanía entre demencia y genialidad es de recio abolengo en la cultura occidental: «Nullum magnum ingenium sine mixtura dementiae fuit» (Séneca, De tranquillitate animi, XVII, 10; véase también Horacio, Odas, IV, XII, 28; Agustín, De civitate Dei, VI, 10, o el parágrafo 283 del Oráculo de Gracián). Sin embargo, Wittgenstein aquí no habla sólo de que una y otra puedan entremezclarse a pesar de su disparidad: sino que, más radicalmente, llega a cuestionar las bases firmes que presuntamente sustentan esa misma disparidad suma.

35 M. O’C. Drury, «A Symposium», en K. T. Fann (ed.), Ludwig Wittgenstein: The Man and His Philosophy, Humanities Press-Harvester Press, Nueva Jersey-Sussex, 1967, 67-71, aquí 67.

36 De esta virtud como algo que se puede normativamente imponer a todas las redes de interpretaciones, en cuanto que es deseable para todas ellas, habla también desde una perspectiva holista A. Valdecantos, Contra el relativismo, Visor, Madrid, 1997; si bien lo hace a partir de argumentos algo diversos a los que aquí figuran (aunque cuentan en algunos pasajes asimismo con Wittgenstein como uno de sus mentores). Véase también N. Malcolm, Wittgenstein: A Religious Point of View?, Routledge, Londres, 1993.

37 Así hacen también R. Bubner, «La svolta ermeneutica del concetto semantico de verità», en G. Vattimo (ed.): Filosofia '88, Laterza, RomaBari, 159-171, 1989; y G. Vattimo, o.c., 52 y 146.

38 H.-G. Gadamer, Verdad y método, trad. de A. Agud y R. de Agapito, Sígueme, Salamanca, 2001, 363-365; «Vom Zirkel des Verstehens», en Gesammelte Werke, vol. II, Mohr, Tubinga, 1986, 57-65.

39 H.-G. Gadamer, «Text und Interpretation», en P. Forget (ed.), Text und Interpretation, Fink, Múnich, 24-55; «Und dennoch: Macht des guten Willens», ibíd., 59-62, aquí 59; «Die Vielfalt der Sprachen und das Verstehen der Welt», en Gesammelte Werke, vol. VIII, Mohr, Tubinga, 1993, 339350 .

40 D. Davidson, «Radical Interpretation», Dialectica, 27 (1973), 313-328.

41 P. A. Rovatti, «L'esercizio del silenzio», en G. Vattimo (ed.), Filosofia '90, Laterza, RomaBari, 1991, 31-42.

42 La que G. Vattimo, «Ermeneutica, nuova koiné», en Etica dell'interpretazione, Rosemberg \& Sellier, Turín, 1989, 38-48, llama «koiné hermenéutica», y a lo que S. Mitchell y M. Rosen (eds.), The Need for Interpretation. Contemporary Conceptions of the Philosopher's Task, The Athlone Press, Londres, 1983, 10, se han referido como importancia «ecuménica» (entre diversas filosofías contemporáneas) de la cuestión de la interpretación.

${ }^{43}$ H.-G. Gadamer, «Die Kunst, Unrecht haben zu können. Gespräch mit dem Philosophen HansGeorg Gadamer», Süddeutsche Zeitung (Feuilleton), 10 y 11-2-90, 16; véase también A. Domingo Moratalla, El arte de poder no tener razón: la hermenéutica dialógica de H. G. Gadamer, Publicaciones de la Universidad Pontificia de Salamanca, Salamanca, 1991. 
44 P. Standish, Beyond the Self. Wittgenstein, Heidegger and the Limits of Language, Ashgate Publishing Group, Aldershot, 1992.

45 Esta tolerancia, además, reviste los rasgos de lo que C. Thiebaut, De la tolerancia, Visor, Madrid, 1999, 56-63, llama «tolerancia positiva» (en oposición a la tolerancia negativa): es decir, no se trata de aceptar meramente y de modo pasivo el hecho de que existen redes de normas posibles alternativas a la nuestra (como tolerantes «negativos»); sino que habría asimismo que «reubicar la carga cognoscitiva que atribuimos a nuestras creencias -por qué son válidas y en qué contextos lo son», así como introducir «importantes modificaciones en lo que consideramos verdadero» (ibíd., 63), al constatar la historicidad y apertura de las propias redes de normas. Baste también apuntar que la cuestión de los límites de la tolerancia que es razonable soportar (ante el loco y el hereje) no se puede delimitar a priori, como si la tolerancia respondiese a un imperativo independiente y previo de las contingentes acciones de los agentes (por el contrario, brota precisamente del hecho de que esas acciones sean contingentes). Pero que el límite de la tolerancia sea elástico no significa que sea infinitamente deformable: como apunta G. Sartori ( $\mathrm{La}$ sociedad multiétnica: pluralismo, multiculturalismo y extranjeros, trad. de M. Á. Ruiz de Azúa, Taurus, Madrid, 2001, 57), también las gomas elásticas pueden acabar por romperse.

46 Ello tampoco significa que entonces las interpretaciones de otros valgan lo mismo que las propias, como ansiaría postular algún relativista: ya que son especialmente las interpretaciones propias aquellas que, precisamente por presentes en nuestro contexto espacio-temporal, nos resultan más constrictivas (y no olvidemos que es precisamente desde una reflexión de nuestro propio contexto normativo desde donde reputamos deseable y normativa la tolerancia -no desde cualquier sitio, como si todos valieran relativistamente igual). No se trata de negar la potencia de las normas entre las que habitamos, sino de añadir a éstas una norma más, la de la tolerancia que se deduce de la evaluación de la cuestión de las normas en general. Por decirlo de otro modo, se trata de comprobar que nuestras interpretaciones son «arbitrarias y no arbitrarias» (Z: 358): son en cierto modo contingentes, y tienen algo de arbitrariedad en sí que nos permite tomárnoslas con cierta ironía; pero a la vez no son arbitrarias, sino impuestas por nuestras circunstancias, lo que nos impide desligarnos de todo asiento concreto de normas, como propone el relativista al reputar que todos esos asientos son, a la postre, iguales. Así, somos tolerantes no gracias a que todo valga igual, sino gracias a que para nosotros vale la norma de la tolerancia en nuestro contexto postmetafísico (precisamente por ser postmetafísico).

47 D. Misgeld y G. Nicholson (eds.), HansGeorg Gadamer on Education, Poetry and History. Applied Hermeneutics, trad. de L. Schmidt y M. Reuss, State University of New York Press, Albany, 1992, 152.

48 P. Winch, «Persuasion», op. cit., 129.

49 Ibíd.

50 S. Shapin, A Social History of Truth, Gentility, Credibility and Scientific Knowledge in Seventeenth Century England, Chicago U. P., Chicago, 1994.

${ }^{51}$ La descripción de esta cita textual está pensada para un filósofo concreto, Frank P. Ramsey, y en referencia a su pensamiento sobre las matemáticas; pero se amolda con igual pertinencia a quienes prefieren optar por renunciar al desafío y a la norma que lanza una «reflexión filosófica» que «intranquiliza», como la versión de postmetafísica que aquí hemos desarrollado de la mano de Wittgenstein. No debe engañar, pues, la referencia al «estado» en el texto que hemos reproducido: no se trata del Estado político más que en el mismo sentido alegórico que asimismo conduce a Wittgenstein a hablar de lo «burgués»; en realidad, se trata ahí de cualquier statu quo de un trasfondo normativo de vida y pensamiento. Lo mismo ocurre en el caso de otro pensador netamente favorable a la «apertura» del pensamiento, como es el resistente italiano Aldo Capitini, quien reputa como «conservador» (en el sentido más lato de la palabra, sin reduccionismos políticos) lo mismo que Wittgenstein califica aquí de «burgués»: véase A. Capitini, $R \boldsymbol{e}$ ligione aperta, Neri Pozza, Vicenza, 1964, 184.

$52 \mathrm{El}$ presente trabajo se ha podido realizar gracias a una beca de investigación postdoctoral concedida por el Gobierno Vasco-Eusko Jaurlaritza para el periodo 2002-04. Que este texto haya sido capaz de suscitar algún interés por ampliar el modo en que en él se aborda el asunto de la normatividad no es, ciertamente, imposible, mas tampoco probable; en todo caso, si se da esta última circunstancia, acaso no sea del todo desatinado acudir a M. Á. Quintana Paz, Normatividad, interpretación y praxis. Wittgenstein en un giro hermenéutico-nihilista, Ediciones Universidad de Salamanca, Salamanca, 2005 (en prensa). 